\title{
Reducing Redundant Alarms in the Pediatric ICU
}

\author{
Maya Dewan ${ }^{1,2}, *$, Lindsay Cipriani ${ }^{2}$, Jacqueline Boyer ${ }^{2}$, Julie Stark ${ }^{2}$, Brandy Seger ${ }^{2}$ and \\ Ken Tegtmeyer ${ }^{1,2}$ \\ 1 Department of Pediatrics, University of Cincinnati School of Medicine, Cincinnati, OH 45229, USA; \\ ken.tegtmeyer@cchmc.org \\ 2 Cincinnati Children's Hospital Medical Center, Division of Critical Care Medicine, Cincinnati, OH 45229, \\ USA; Lindsay.Cipriani@cchmc.org (L.C.); Jacquelyn.Boyer@cchmc.org (J.B.); Julie.stark@cchmc.org (J.S.); \\ brandy.seger@cchmc.org (B.S.) \\ * Correspondence: maya.dewan@cchmc.org; Tel.: +1-513-636-4334
}

Received: 27 January 2019; Accepted: 21 February 2019; Published: 23 February 2019

\begin{abstract}
Physiologic monitors generate alarms to alert clinicians to signs of instability. However, these monitors also create alarm fatigue that places patients at risk. Redundant alarms have contributed to alarm fatigue without improving patient safety. In this study, our specific aim was to decrease the median percentage of redundant alarms by $50 \%$ within 6 months using the Model for Improvement. Our primary outcome was to lower the percentage of redundant alarms. We used the overall alarm rate per patient per day and code blue events as balancing metrics. We completed three Plan-Do-Study-Act cycles and generated run charts using standard industry criteria to determine the special cause. Ultimately, we decreased redundant alarms from a baseline of $6.4 \%$ of all alarms to $1.8 \%$, surpassing our aim of a $50 \%$ reduction. Our overall alarm rate, one of our balancing metrics, decreased from 137 alarms/patient day to 118 alarms/patient day during the intervention period. No code blue events were determined to be related to incorrect setting of alarms. Decreasing redundant alarms is safe and feasible. Following a reduction in redundant alarms, more intensive alarm reduction methods are needed to continue to reduce alarm fatigue while keeping patients safe.
\end{abstract}

Keywords: alarm fatigue; critical care; pediatrics

\section{Introduction}

Physiologic monitors generate alarms to alert clinicians to signs of instability. Prior research has demonstrated that the pediatric intensive care unit (PICU) experiences a higher proportion of alarms than pediatric wards [1], and more than $80 \%$ of these alarms are nonactionable [2-6]. High alarm rates lead to interruptions [7] and alarm fatigue [2,8,9] that put patients at risk of harm. Alarm fatigue occurs when humans learn to ignore alarms or respond slowly to alarms when exposed to high false alarm rates [10,11]. National surveys of healthcare providers suggest that alarm fatigue is an important hospital safety issue $[12,13]$. Within our PICU, a serious safety event occurred in which alarm fatigue was determined to be a contributing factor [14]. In response to this event, a multidisciplinary team, led by physician and nurse co-leaders, was formed to address alarm fatigue.

Sensitive to concerns around alarm fatigue prior to this event, our unit tracked and evaluated the overall alarm burden within our PICU on a quarterly basis. In July 2017, six months prior to the safety event, we transitioned to a new monitor company and revised alarm parameters. Through this transition and adjustment in baseline physiologic parameters, we demonstrated a decrease in physiologic monitor alarms from an average of 160 alarms/patient/day to 137 alarms/patient/day. However, due to this transition, confusion remained around the setting and adjusting of alarm parameters, leading to duplicate alarms for the same conditions and unnecessary alarms that were accidentally turned on. We chose to define these duplicate or unnecessary alarms as redundant alarms 
or alarms that contributed to alarm fatigue without improving patient safety (e.g., duplicate respiratory rate alarms, patient data alarms, duplicate oxygen saturation alarms, and patient perfusion alarms). Although redundant alarms only comprised $9.6 \%$ of our total alarms when we began, we hypothesized that the removal of redundant alarms would increase the alarm salience (i.e., the proportion of true alarms), thereby leading to decreased alarm fatigue.

Our specific aim was to decrease the median percentage of redundant alarms by $50 \%$, using the Model for Improvement, within 6 months. The Model for Improvement is a framework to guide the improvement of work throughs small scale tests of change using Plan-Do-Study-Act cycles [15].

\section{Materials and Methods}

\subsection{Setting}

This quality improvement (QI) project using the Model for Improvement [15] was completed in a 35-bed tertiary care medical-surgical PICU, which averages over 2500 admissions per year. The transition to a new monitor manufacturer occurred in July 2017. All patients were placed on continuous pulse oximetry and cardiorespiratory monitoring on admission, and continuous monitoring remained on for the duration of a patient's PICU stay, as per hospital policy. Audible alarms occurred within the patient's room, as well as at a central monitoring station for groups of eight to ten beds, based on the organization of our PICU into four distinct pods. Alarm parameters were set by nurses within age specific guardrails, and a physician order was required to set parameters outside of these recommended values. We received institutional support in the form of a QI advisor, who helped to facilitate this project. This project was determined to be non-human subjects research.

\subsection{Measures}

Initial baseline alarm data was collected for five months prior to intervention. The number of redundant alarms and total alarms within the PICU were tracked weekly. Our primary outcome was to reduce the percentage of redundant alarms. We also tracked the individual redundant alarm types (e.g., duplicate respiratory rate alarms, patient data alarms, duplicate oxygen saturation alarms, and patient perfusion alarms) as secondary outcomes. We followed two balancing metrics: overall alarm rate per patient day and code blue events. We tracked overall alarm rate per patient per day to assure that the reduction in percentage of redundant alarms was related to decreasing redundant alarms and not an overall increase in other alarm types. We performed a structured review after all code events to assess whether appropriate alarm settings contributed to the event.

\subsection{Planning Key Interventions}

Initially, we assembled a group of nursing and physician providers to derive a key driver diagram (Figure 1). After engaging key stakeholders, presenting baseline data on redundant alarms, and completing a simplified failure mode effects analysis, we initiated our first Plan-Do-Study-Act (PDSA) cycle [16], which was standardized in June 2018 (Figure 2). Through our failure mode affects analysis, we identified a lack of standardization with the monitor set up and during patient transitions as a common cause of redundant alarms. To tackle this problem, we standardized the monitor set up and patient transitions by using laminated checklists attached to the monitors. These cards included screenshots and direct guidance for nurses on proper monitor set-up for patient admission and transfer. These cards provided step by step instructions on entering patient data, setting alarm parameters, adjusting alarm parameters, and transferring patient data when a patient was admitted from another care area (Figure 3). The appropriate position of the laminated cards was added to the room set-up checklist to ensure that they were present in the rooms at the time of admission. 


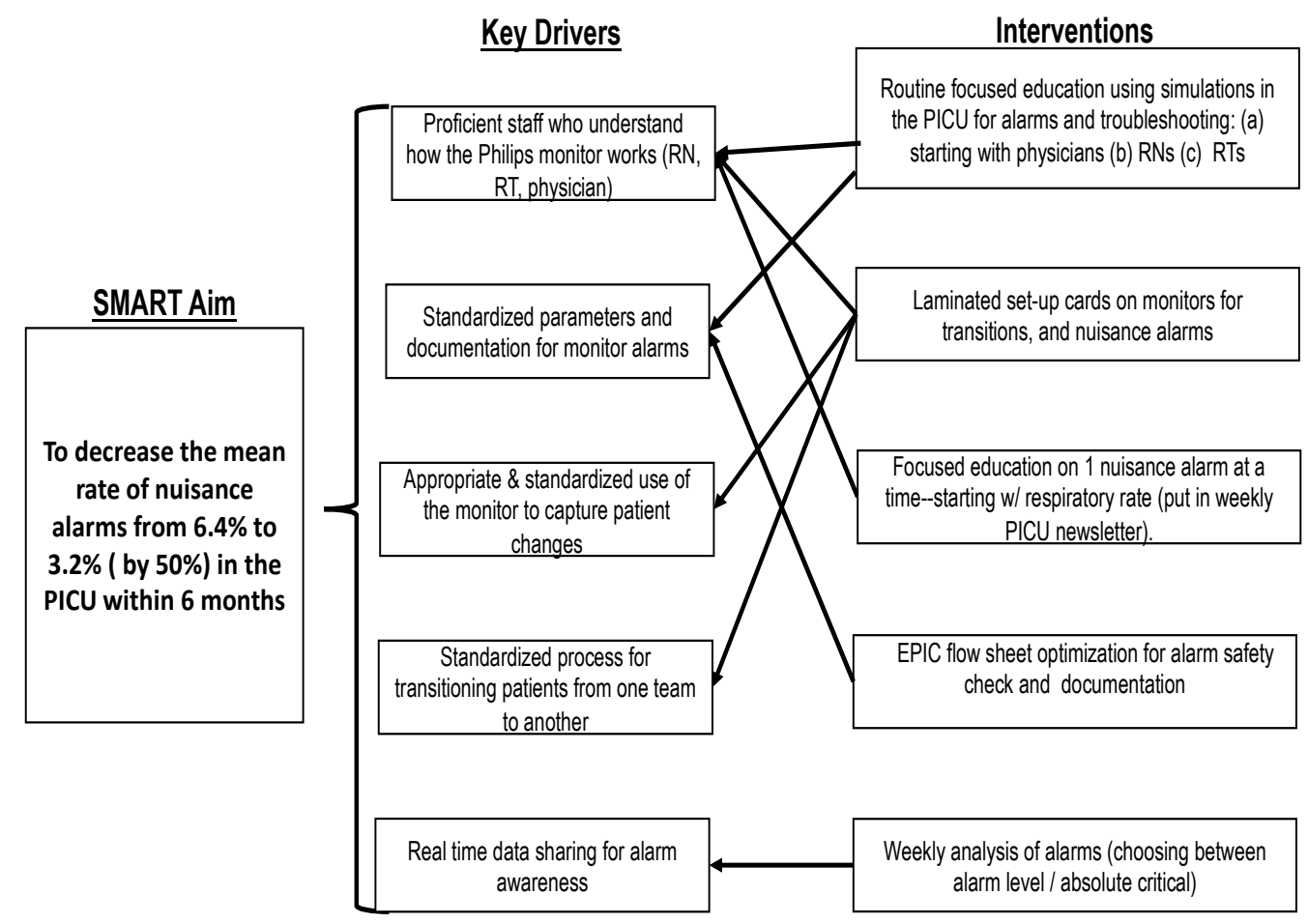

Abbreviations: RN-registered nurse, RT-respiratory therapist

Figure 1. Key driver diagram to reduce redundant alarms within the pediatric intensive care unit (PICU).

\section{PDSA Cycle 1}

\section{STANDARDIZATION}

(June 2018): Laminated

cards attached to

monitor with

screenshots to outline

admission of patients

and common mistakes

contributing to

redundant alarms

\section{PDSA Cycle 3}

\section{RELIABILITY}

(September 2018):

Alarm documentation and ordering changed within the electronic medical record to support proper setting of alarms

Figure 2. Review of the three Plan-Do-Study-Act (PDSA) Cycles Implemented. 


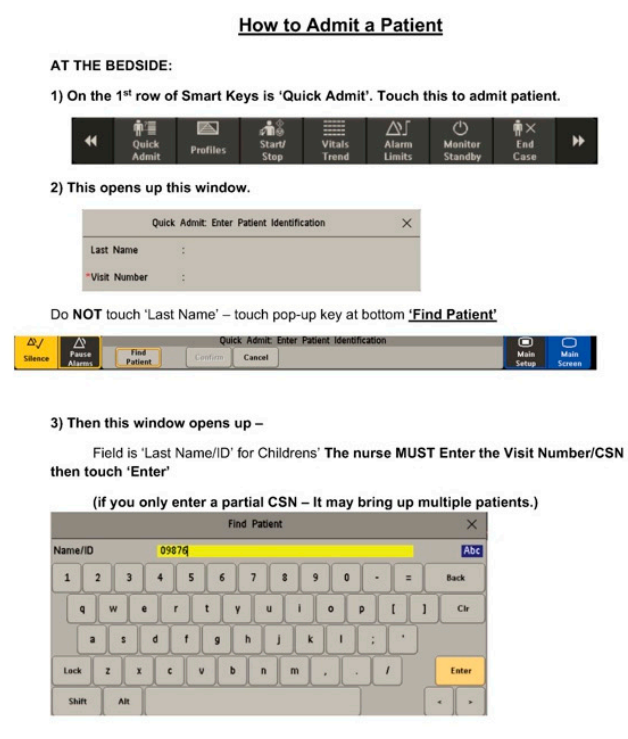

4) This brings up a patient with the Visit Number you typed in. Please verify it is the correct patient you need to admit.
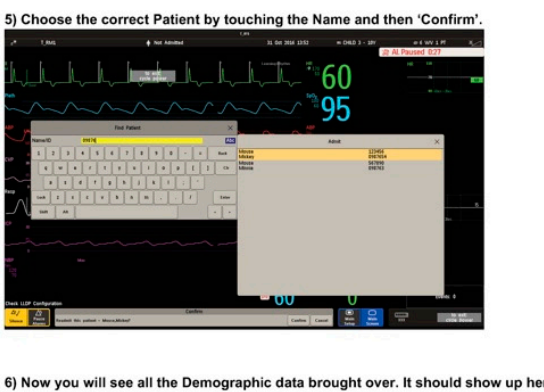
a) Now you will see all the Demograph

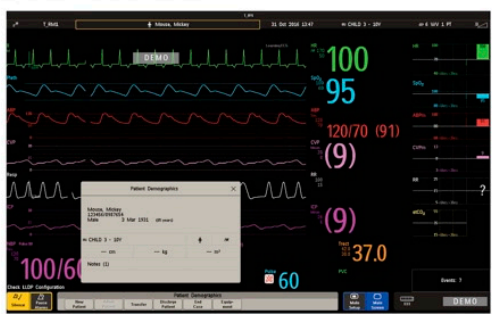

-3.- Warning - do not delay in entering this information. ONCE YOU 'CONFIRM' THE INFORMATION - ANY DATA PRIOR WILL BE ERASED. If you have already been

Figure 3. Example of one of the laminated cards attached to the monitor to assist nurses in the process of how to accurately admit a patient to the monitor.

The second PDSA cycle focused on educational efforts completed for nurses at daily huddles, through weekly email newsletter, and with direct bedside education, in July 2018. Using materials from the manufacturer, as well as internally developed educational materials, we focused on how redundant alarms happen through improper monitor set up. Tackling one redundant alarm per week, we provided in depth explanations of the causes of redundant alarms and offered explanations on why they were redundant and unnecessary. Reinforcing the information on the laminated bedside cards, nursing educators provided one on one direct bedside education. Additionally, nurses were specifically instructed to identify and troubleshoot redundant alarms, once monitor set up was complete.

The third PDSA cycle focused on sustained reliability in September 2018. By adapting alarm documentation and ordering via the electronic medical record we reinforced proper alarm settings. Prior electronic medical record documentation of alarm parameters did not include alarm documentation using the correct terminology, which created confusion. Specifically, with our old monitor manufacturer, the setting of pulse oximetry parameters was a simple adjustment of the range. The documentation within our electronic medical record only allowed for a single field documentation of range. With the transition to our new manufacturer, differential time delays were placed on pulse oximetry alarms within the Philips monitor (Philips Healthcare, Amsterdam, Netherlands) ranges to decrease unnecessary alarms while maintaining safety. The new documentation built into the electronic medical record during PDSA cycle 3 allowed for documentation of ranges with differential time delays, to reinforce proper monitor set up using consistent terminology. All three PDSA cycles continued throughout the study period of three months. PDSA cycles 1 and 3 have remained during the sustainability phase, which continues at the time of publication.

\subsection{Analysis}

We generated run charts using Excel (Microsoft, Redmond, WA, USA) macros developed by our institution. Standard industry criteria were used to determine if observed changes in measures were due to chance random variations (common cause variations) or due to specific assignable causes-in this case, the intervention (special cause variation). [17] We used accepted run chart rules to determine when the median line should be adjusted: eight or more consecutive points above or below the centerline indicates that a special cause has occurred [16]. 


\section{Results}

At baseline, redundant alarms composed $6.4 \%$ of all alarms at a rate of 137 alarms/patient/day. Following our first PDSA cycle, we achieved a special cause, so our baseline was adjusted to the new median of 3.4\%. Following our second and third PDSA cycles, we demonstrated sustained improvement below our goal line of $3.2 \%$, with our median currently at $1.8 \%$ (Figure 4 ). Our overall alarm rate did not increase during this work and is now 118 alarms/patient/day. This decrease in overall alarm rate may be a result of the work described here to reduce redundant alarms or may be attributable to natural variation. No code blue events within the PICU during the intervention period $(\mathrm{N}=18)$ were determined to be related to the incorrect setting of alarms, and there was no increase in any specific redundant alarm types.

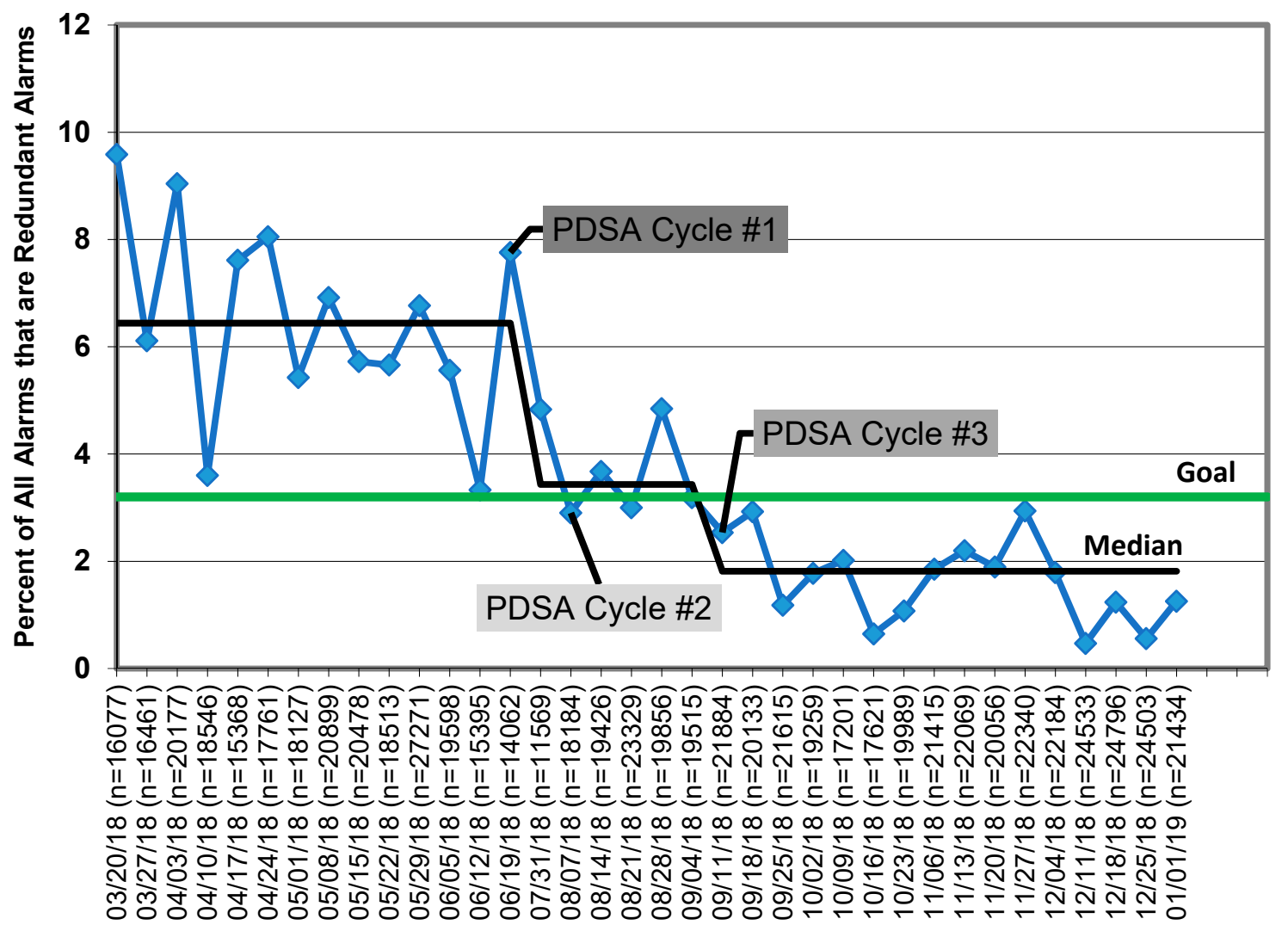

\section{Week}

Figure 4. Run chart of percentage of redundant alarms in the PICU from March 2018 to January 2019.

\section{Discussion}

Using the Model for Improvement, we were able to decrease redundant alarms by $50 \%$ in three months and have demonstrated sustainability for an additional three months. We chose to first tackle redundant alarms in our ongoing work to decrease alarm fatigue because these alarms contribute to alarm fatigue without improving patient safety. Addressing redundant alarms is a simple first step in a framework for reducing alarm fatigue [18], as this step allows for the removal of alarms that are known to be unnecessary and not predictive of patient deterioration. Achieving key stakeholder buy in for the reduction of alarms can be difficult due to safety concerns, so choosing to begin with redundant alarms allows for a safe and simple demonstration of success in alarm reduction.

Prior work has sought to identify alarms that do not require a clinician response $[19,20]$ as a starting point for reducing alarm fatigue; however, these approaches have two major flaws. First, it is impossible to determine a priori which alarms will not be actionable if they indicate true physiological 
derangements, even if those derangements do not require a response. Second, these approaches are often time consuming to complete on a large scale without substantial resources [19,21,22]. Using the term "redundant alarms" allows for an a priori assignment of non-action to these alarms because they are, by definition, unnecessary. We would encourage all centers to first identify their redundant alarms and work to eliminate them. Although redundant alarms comprised $<10 \%$ of our total alarms, we hypothesized that the removal of redundant alarms would increase the alarm salience (i.e., the proportion of true alarms) leading to decreased alarm fatigue.

After undertaking work to reduce or remove redundant alarms, centers must put active interventions into place to target further reduction. For non-ICU floors, prior successful research on the reduction of pediatric alarms involved instituting a cardiac monitor care process that included ordering of age-based parameters, daily replacement of electrodes, individualized assessment of parameters, and a reliable method to discontinue monitoring. Reliance on monitor discontinuation as a main approach to decreasing alarms is not feasible in our setting, as patients in the PICU are critically ill and, therefore, require continuous monitoring for the notification of desaturation, arrhythmia, or abnormal hemodynamics [23]. Additional work both in the PICU and on the pediatric ward to target alarm reduction through individual parameter adaptations via a huddle intervention has shown promise $[24,25]$ and may be an effective next step for many centers.

There are limitations to this study. First, we focused only on redundant alarms to allow for a reduction in nonactionable alarms with limited potential for adverse events; however, this approach excludes the majority of alarms heard in the PICU. Second, the balancing metrics of Code Blue events are rare events and therefore we may have been underpowered to find them. We experience on average $2-3$ code blue events per month in the PICU, all of which are reviewed in a standardized fashion. During the course of this project, 18 code blue events were reviewed, and none were found to be related to monitor alarm changes. As the PICU has multiple systems to catch deteriorating patients in addition to monitor alarms, it is possible that our changes may have put patients at risk without it progressing to a code event. Although possible, we believe that this is highly unlikely, since we were reducing redundant alarms. Third, this study was completed at a single center and, therefore, may lack generalizability.

\section{Conclusions}

Here, we demonstrated that decreasing redundant alarms is a safe and feasible first step to target alarm reduction, while developing key stakeholder buy in and collecting further data. This QI project has transitioned from a temporary project to a long term area of focus for our nursing education council to support sustainability. Next, we plan to spread this work to the cardiac intensive care unit and neonatal intensive care unit within our institution. Following internal spread, more intensive alarm reduction methods are needed to continue to reduce alarm fatigue, while keeping patients safe. Next, we plan to work on the reduction of oxygen saturation alarms, as we move to continue to decrease overall alarm fatigue in our PICU.

Author Contributions: Conceptualization, M.D., B.S., J.B. and L.C.; methodology, M.D., B.S., K.T., J.S.; formal analysis, M.D., B.S.; writing_original draft preparation, M.D., B.S.; writing—review and editing, M.D., B.S., J.S., J.B., L.C. and K.T.; supervision, K.T.

Funding: This research received no external funding.

Conflicts of Interest: The authors declare no conflict of interest. 


\section{References}

1. Schondelmeyer, A.C.; Bonafide, C.P.; Goel, V.V.; Blake, N.; Cvach, M.; Sucharew, H.; Simmons, J.M.; Brady, P.W. The frequency of physiologic monitor alarms in a children's hospital. J. Hosp. Med. 2016, 11, 796-798. [CrossRef] [PubMed]

2. Bonafide, C.P.; Lin, R.; Zander, M.; Graham, C.S.; Paine, C.W.; Rock, W.; Rich, A.; Roberts, E.; Fortino, M.; Nadkarni, V.M.; et al. Association between exposure to nonactionable physiologic monitor alarms and response time in a children's hospital. J. Hosp. Med. 2015, 10, 345-351. [CrossRef] [PubMed]

3. Lawless, S.T. Crying wolf: False alarms in a pediatric intensive care unit. Crit. Care Med. 1994, 22, 981-985. [CrossRef] [PubMed]

4. Tsien, C.L.; Fackler, J.C. Poor prognosis for existing monitors in the intensive care unit. Crit. Care Med. 1997, 25, 614-619. [CrossRef] [PubMed]

5. Talley, L.B.; Hooper, J.; Jacobs, B.; Guzzetta, C.; McCarter, R.; Sill, A.; Cain, S.; Wilson, S.L. Cardiopulmonary monitors and clinically significant events in critically ill children. Biomed. Instrum. Technol. 2011, 45, 38-45. [CrossRef] [PubMed]

6. Rosman, E.C.; Blaufox, A.D.; Menco, A.; Trope, R.; Seiden, H.S. What are we missing? arrhythmia detection in the pediatric intensive care unit. J. Pediatr. 2013, 163, 511-514. [CrossRef] [PubMed]

7. Westbrook, J.I.; Li, L.; Hooper, T.D.; Raban, M.Z.; Middleton, S.; Lehnbom, E.C. Effectiveness of a Do not interrupt' bundled intervention to reduce interruptions during medication administration: A cluster randomised controlled feasibility study. BMJ Qual. Saf. 2017, 26, 734-742. [CrossRef] [PubMed]

8. Bonafide, C.P.; Localio, A.R.; Holmes, J.H. Video analysis of factors associated with response time to physiologic monitor alarms in a children's hospital. JAMA Pediatr. 2017, 171, 524-531. [CrossRef] [PubMed]

9. Chopra, V.; McMahon, L.F. Redesigning Hospital Alarms for Patient Safety. JAMA 2014, 311, 1199. [CrossRef] [PubMed]

10. The Joint Commission. Hospital National Patient Safety Goals. 2019. Available online: https://www. jointcommission.org/assets/1/6/2019_HAP_NPSGs_final2.pdf (accessed on 22 February 2019). [CrossRef]

11. ECRI Institute. Top 10 Patient Safety Concerns for Healthcare Organizations 2016. ECRI Inst. Available online: https://www.ecri.org/EmailResources/PSRQ/Top10/2016_Top10_ExecutiveBrief_final.pdf (accessed on 22 February 2019). [CrossRef]

12. Sendelbach, S.; Funk, M. Alarm fatigue: A patient safety concern. AACN Adv. Crit. Care 2013, $24,378$. [CrossRef] [PubMed]

13. Cvach, M. Monitor alarm fatigue: An integrative review. Biomed. Instrum. Technol. 2012, 46, $268-277$. [CrossRef] [PubMed]

14. Korniewicz, D.M.; Clark, T.; David, Y. A national online survey on the effectiveness of clinical alarms. Am. J. Crit. Care 2008, 17, 36-41. [PubMed]

15. Langley, G.J.; Moen, R.D.; Nolan, K.M.; Nolan, T.W.; Norman, C.L.; Provost, L.P. The Improvement Guide-A Practical Approach to Enhancing Organizational Performance; John Wiley \& Sons, Inc.: Hoboken, NJ, USA, 2009. [CrossRef]

16. Moen, R.D.; Nolan, T.W.; Provost, L.P. Quality Improvement through Planned Experimentation; McGraw-Hill: New York, NY, USA, 1999.

17. Benneyan, J.C.; Lloyd, R.C.; Plsek, P.E. Statistical process control as a tool for research and healthcare improvement. BMJ Qual. Saf. 2003, 12, 458-464. [CrossRef]

18. Karnik, A.; Bonafide, C.P. A framework for reducing alarm fatigue on pediatric inpatient units. Hosp. Pediatr. 2015, 5, 160-163. [CrossRef] [PubMed]

19. Bonafide, C.P.; Zander, M.; Graham, C.S.; Weirich Paine, C.M.; Rock, W.; Rich, A.; Roberts, K.E.; Fortino, M.; Nadkarni, V.M.; Lin, R.; et al. Video methods for evaluating physiologic monitor alarms and alarm responses. Biomed. Instrum. Technol. 2014, 48, 220-230. [CrossRef] [PubMed]

20. Paine, C.W.; Goel, V.V.; Ely, E.; Stave, C.D.; Stemler, S.; Zander, M.; Bonafide, C.P. Systematic Review of Physiologic Monitor Alarm Characteristics and Pragmatic Interventions to Reduce Alarm Frequency. J. Hosp. Med. 2016, 11, 136-144. [CrossRef] [PubMed]

21. Inokuchi, R.; Sato, H.; Nanjo, Y.; Echigo, M.; Tanaka, A.; Ishii, T.; Matsubara, T.; Doi, K.; Gunshin, M.; Hiruma, T.; et al. The proportion of clinically relevant alarms decreases as patient clinical severity decreases in intensive care units: A. pilot study. BMJ Open 2013, 3, e003354. [CrossRef] [PubMed] 
22. Drew, B.J.; Harris, P.; Zegre-Hemsey, J.K.; Mammone, T.; Schindler, D.; Salas-Boni, R.; Bai, Y.; Tinoco, A.; Ding, Q.; Hu, X. Insights into the problem of alarm fatigue with physiologic monitor devices: A comprehensive observational study of consecutive intensive care unit patients. PLoS ONE 2014, 9, e110274. [CrossRef] [PubMed]

23. Dandoy, C.E.; Davies, S.M.; Flesch, L.; Hayward, M.; Koons, C.; Coleman, K.; Jacobs, J.; McKenna, L.A.; Olomajeye, A.; Olson, C.; et al. A Team-Based Approach to Reducing Cardiac Monitor Alarms. Pediatrics 2014, 134, e1686-e1694. [CrossRef] [PubMed]

24. Dewan, M.; Wolfe, H.; Lin, R.; Ware, E.; Weiss, M.; Song, L.; MaMurchy, M.; Davis, D.; Bonafide, C.P. Impact of a Safety Huddle-Based Intervention on Monitor Alarm Rates in Low-Acuity Pediatric Intensive Care Unit Patients. J. Hosp. Med. 2017, 12, 652-657. [CrossRef] [PubMed]

25. Bonafide, C.P.; Localio, A.R.; Stemler, S.; Ahumada, L.; Dewan, M.; Ely, E.; Keren, R. Safety Huddle Intervention for Reducing Physiologic Monitor Alarms: A Hybrid Effectiveness-Implementation Cluster Randomized Trial. J. Hosp. Med. 2018, 13, 609-615. [CrossRef] [PubMed]

(C) 2019 by the authors. Licensee MDPI, Basel, Switzerland. This article is an open access article distributed under the terms and conditions of the Creative Commons Attribution (CC BY) license (http:/ / creativecommons.org/licenses/by/4.0/). 